Tropical Journal of Pharmaceutical Research September 2015; 14 (9): 1541-1547

ISSN: $1596-5996$ (print); 1596-9827 (electronic)

(c) Pharmacotherapy Group, Faculty of Pharmacy, University of Benin, Benin City, 300001 Nigeria.

All rights reserved.

Available online at http://www.tjpr.org

Original Research Article

http://dx.doi.org/10.4314/tjpr.v14i9.1

\title{
Preparation and Characterization of Colon-Specific Microspheres of Diclofenac for Colorectal Cancer
}

\author{
Tong Dang, Ying Cui, Yan-Dong Chen, Xian-Mei Meng, Bo-Fu Tang and Jin-Bao \\ Wu* \\ Inner Mongolia Institute of Digestive Diseases, the Second Affiliated Hospital of Baotou Medical College, Baotou 014030, China
}

*For correspondence: Email: wujinbao2143@gmail.com; Tel/Fax: 0086-472-3169715

Received: 12 February 2015

Revised accepted: 26 July 2015

\begin{abstract}
Purpose: To prepare and evaluate colon specific drug delivery system of diclofenac sodium for highly localized delivery to the colon.

Methods: The colon specific drug delivery system was prepared as matrix-type microspheres using Ethyl Cellulose (EC), Cellulose Acetate Phthalate (CAP), and Eudragit L 100-55 by the Solvent Evaporation Method. Microspheres were evaluated for physical properties like drug content, particle size, bulk density and angle of repose.

Results: The size range of the microcapsules was 228 to $608 \mu \mathrm{m}$ while drug content was between 74.49 and $91.50 \%$ depending on the polymer used and the polymer ratio. Mean bulk density was $<1.2$ $\mathrm{g} / \mathrm{ml}$ which indicates the good flow properties, while angle of repose was $<40^{\circ}$, indicating free-flowing properties. The microspheres were spherical in shape with smooth and nonporous surface, except that the microspheres containing EC and CAP exhibited a rough and porous surface. The microspheres containing Eudragit $L$ 100-55 in combination with other polymers gave better sustained release (78.9 and $76.6 \%$ at the end of $8 \mathrm{~h}$ for formulation F4 and F5, respectively) than the others.

Conclusion: Microspheres prepared with drug: EC: CAP ratio of 1:2:1 show the highest drug content, possess good flow properties and surface morphology, as well as promising drug release for colon specific drug delivery of diclofenac sodium for possible treatment of colorectal cancer.
\end{abstract}

Keywords: Diclofenac, Colorectal cancer, Microspheres, Ethyl cellulose, Cellulose acetate phthalate, Eudragit L $100-55$

Tropical Journal of Pharmaceutical Research is indexed by Science Citation Index (SciSearch), Scopus, International Pharmaceutical Abstract, Chemical Abstracts, Embase, Index Copernicus, EBSCO, African Index Medicus, JournalSeek, Journal Citation Reports/Science Edition, Directory of Open Access Journals (DOAJ), African Journal Online, Bioline International, Open-J-Gate and Pharmacy Abstracts

\section{INTRODUCTION}

The oral route of drug administration is the most convenient and important method of administering drugs for systemic effect due to patient acceptance and ease of administration. An oral colon specific drug delivery system is intended to retard the drug release in the stomach and small intestine, but allow complete release in colon for the various diseases like colorectal cancer and inflammatory bowel diseases [1-3]. Studies have consistently demonstrated that regular use (at least two doses per week) of nonsteroidal antiinflammatory drugs (NSAIDs) is associated with a reduced risk of colorectal cancer. Epidemiological studies have indicated that nonsteroidal anti-inflammatory drugs (NSAIDs), including indomethacin, aspirin, and sulindac, exhibit anti-cancer activity in colorectal cancer [4$6]$.

Colon specific drug delivery systems target the drug release in the colon only without being 
dissolved/release in upper GIT. The drug should degrade neither in upper GIT nor in the colon (dissolution site) and should release the drug only after reaching the colon. The prerequisite is that the drug should be well absorbed from the colon (like glibenclamide, diclofenac, theophylline, ibuprofen, etc) [7].

Natural polysaccharides e.g. pectin, chitosan, guar gum, dextran, inulin, cyclodextrin, xanthum gum, etc are extensively used for the development of solid oral dosage forms for colonic delivery of drugs [8]. There are various synthetic polymers which are used for colon targeted drug delivery. These can also be called as $\mathrm{pH}$-dependent polymers.

The most commonly used $\mathrm{pH}$-dependent polymers are derivatives of acrylic acid and cellulose. The $\mathrm{pH}$ dependent polymers used in colon specific drug delivery are insoluble at low $\mathrm{pH}$ levels but become increasingly soluble as $\mathrm{pH}$ rises. e.g., Eudragit and shellac [9].

Microparticles are a type of drug delivery systems where the particle size ranges from one micron to few $\mathrm{mm}$. Microspheres are characteristically free flowing powders consisting of proteins and synthetic polymers, biodegradable in nature and having a particle size less than $200 \mu \mathrm{m}$ (normally the range is also acceptable up to $1000-1500 \mu \mathrm{m}$ ) [10].

Dicolofenac sodium (DS) is a well-known nonsteroidal anti-inflammatory drug (NSAID). It is well absorbed in the colon, and colon specific release can be used for the treatment of various diseases like colorectal cancer and inflammatory bowel diseases [11-13].

Diclofenac is an effective agent in the cancer regression as the traditional NSAIDs (COX-1 inhibitor) or specific COX-2 inhibitor [14]. Diclofenac decreases inflammation at tissues sites and exert preventive effect against colon cancer that seems to be due to increased colon cell apoptosis [15]. As an alternative strategy of colorectal cancer treatment the colon specific delivery of NSAIDs like diclofenac is well accepted and investigated $[16,17]$.

Therefore, the present study investigates the colon specific delivery of diclofenac sodium in matrix-type microspheres prepared with ethyl celluolose, cellulose acetate phthalate and Eudragit L 100 .

\section{EXPERIMENTAL}

Diclofenac sodium, sodium alginate, guar gum and xanthan gum were procured from Sigma Aldrich, USA. All other chemicals used were of analytical grade.

\section{Preparation of microspheres}

The microspheres of diclofenac sodium were prepared by solvent evaporation technique using ethyl cellulose, cellulose acetate phthalate (CAP) and Eudragit L 100-55 (Table 1).

An accurately weighed amount of polymer was dissolved in $30 \mathrm{ml}$ of acetone in a beaker. Weighed amount of Verapamil Hydrochloride, was dispersed, in this solution and stirred for 15 min for complete dispersion. The dispersion was poured into $100 \mathrm{ml}$ of light mineral oil containing $1.3 \%$ span 80 and stirred for $5 \mathrm{~h}$ at $1000 \mathrm{rpm}$ using mechanical stirrer at room temperature. The light mineral oil was used as the microencapsulating vehicle and SPAN 80 as an emulsifying agent. During the $5 \mathrm{~h}$ stirring period, acetone was completely removed by evaporation. The light mineral oil was decanted and the collected microspheres were washed thrice with $50 \mathrm{ml}$ of $\mathrm{n}$-hexane at room temperature, after which the microcapsules were separated by filtration. The microcapsules were kept for $12 \mathrm{~h}$ at room temperature for drying and stored in desiccators for complete removal of moisture.

Table 1: Composition of colon specific microspheres of diclofenac sodium

\begin{tabular}{lcccccc}
\hline Ingredient & F1 & F2 & F3 & F4 & F5 & F6 \\
\hline Diclofenac sodium & 1 & 1 & 1 & 1 & 1 & 1 \\
EC & 3 & $\ldots$ & 2 & 2.5 & $\ldots$ & 1 \\
CAP & $\ldots$ & 3 & 1 & $\ldots$ & 2.5 & 1 \\
Eudragit L100-55 & $\ldots$ & $\ldots$ & $\ldots$ & 0.5 & 0.5 & 1 \\
\hline
\end{tabular}

Key: $E C=$ ethyl cellulose, $C A P=$ cellulose acetate phthalate 


\section{Determination of yield}

The percentage yield was calculated from the weight of dried microspheres recovered from each batch in relation to the sum of the initial weight of starting materials. Yield was calculated using Eq 1.

Yield $(\%)=(\mathrm{Mp} / \mathrm{Mt}) 100$

where $\mathrm{Mp}$ and $\mathrm{Mt}$ are the practical mass of microspheres and theoretical mass of polymer + drug, respectively.

\section{Evaluation of micromeritic properties}

\section{Particle size}

Using optical microscopy method particle size of the formulations was determined. At least 100 microspheres were analyzed for each formulation and the mean particle size was calculated.

\section{Angle of repose}

The flow property of the prepared microcapsules was determined by the angle of repose, using fixed funnel method. The known quantities of microcapsules were passed through the funnel and the heap was formed on paper. The formed heap on paper was encircled. From the radius of the circle and height of the conical heap, angle of repose was calculated.

\section{Compressibility index}

The loose bulk density ( $\rho b)$ and the tap ( $\rho t)$ density of the microspheres were measured in a measuring cylinder $[10,18]$. An amount of $1 \mathrm{~g}$ of prepared microspheres was filled in $10 \mathrm{ml}$ graduated cylinder. The initial volume was noted then cylinder was tapped on wooden surface. The density was measured by tapping the cylinder 100 times (from the height of one inch) at the rate of $240 \mathrm{taps} / \mathrm{min}$. Each determination was carried out in triplicate and the densities were calculated from the mean of the three determinations. Density was calculated as the ratio of mass to volume, compressibility index (Cl) using Eq 2 and Hausner's ratio (HR) using Eq 3.

$$
\begin{aligned}
& \mathrm{Cl}=\{(\rho \mathrm{t}-\rho \mathrm{pb}) / \rho \mathrm{t}\} 100 \\
& \mathrm{HR}=(\rho \mathrm{t} / \rho \mathrm{\rho b}) 100 \ldots \ldots
\end{aligned}
$$

\section{Evaluation of drug content}

The drug content was calculated by taking the microspheres equivalent to $100 \mathrm{mg}$ of drug.
Microspheres were finely crushed, dissolved in $100 \mathrm{ml}$ of methanol through stirring on magnetic stirrer for $1 \mathrm{~h}$ and then filtered. Then the sample was withdrawn, filtered, diluted suitably and measured spectrophotometrically (Lambda 25 Perkin Elmer, UV/Visible Spectrophotometer, USA) at $276 \mathrm{~nm}$ for the drug content.

\section{Characterization of surface morphology}

To assess the surface morphology and particle size of the microspheres, SEM of the microspheres was performed by scanning electron microscope (Carl Zeiss SMT Evo Series).

\section{In vitro dissolution studies}

The release studies of diclofenac from microspheres were performed in USP dissolution apparatus type I, at $50 \mathrm{rpm}$ in $900 \mathrm{ml}$ of $0.1 \mathrm{~N}$ $\mathrm{HCl}, \mathrm{pH} 6.8$ Phosphate Buffer and $\mathrm{pH} 7.4$ phosphate buffer with $4 \%$ rat cecal content. Simulation of gastrointestinal transit conditions were achieved by using different dissolution media. The drug release studies was conducted in $\mathrm{pH} 1.2$ buffer solution for the first $2 \mathrm{~h}$ to mimic the condition in the stomach and in $\mathrm{pH} 6.8$ phosphate buffer for $3 \mathrm{~h}$. The dissolution medium was then replaced with $\mathrm{pH} 7.4$ phosphate buffer containing rat cecal content and the study continued for the end of $8 \mathrm{~h}$. At the specified time, samples were withdrawn and then it was replaced with fresh buffer solution maintained at $37{ }^{\circ} \mathrm{C}$. The samples were withdrawn, diluted suitably and then assayed spectrophotometrically for the drug release at $276 \mathrm{~nm}$.

\section{Kinetic analysis of drug release}

To determine the mechanism of drug release and release rate kinetics of the drug from the microspheres, the in vitro drug release data was fitted to various kinetic models representing zeroorder $(Q \mathrm{v} / \mathrm{s} t)$, first-order $\left(\log \left(Q_{0}-Q\right) \mathrm{v} / \mathrm{s} t\right)$, Higuchi's square root of time $\left(Q v / s t_{1 / 2}\right)$ and Korsemeyer peppas double $\log$ plot $(\log Q$ v/s $\log t$ ), respectively, where $Q$ is the cumulative percentage of drug released at time $t$ and $\left(Q_{0}-Q\right)$ is the cumulative percentage of drug remaining after time, $\mathrm{t}$ [17-19].

\section{Statistical analysis}

The results were expressed as mean \pm standard deviations (SD). Statistical analysis was carried out using analysis of variance (ANOVA) on GraphPad Prism(C) 4.0 (Graphpad Software Inc. San Diego, CA, USA). $P<0.05$ was considered significant. 


\section{RESULTS}

In the present work, the colon specific microspheres of diclofenac sodium were prepared using solvent evaporation method. For the colon targeting synthetic polymers namely ethyl cellulose (EC), cellulose acetate phthalate (CAP), and Eudragit L 100-55 were used to prepare the microspheres. The prepared formulations of different drug polymer ratio were evaluated for physical properties like particle size, bulk density, tap density, angle of repose and percent drug encapsulation efficiency and in vitro drug release study.

\section{Micromeritic properties}

The physical parameters (Table 2) such as bulk density, tapping density, compressibility index and angle of repose were evaluated, which provide the basis for optimization of the flow property of microspheres. All the microspheres of various formulations showed good flow property with an angle of repose less than $40^{\circ}$ in the range of 28 to $35^{\circ}$. Bulk density is indicative of the package properties of the microspheres. All the microspheres of different formulation were less than $1.2 \mathrm{~g} / \mathrm{ml}$. The size range of various microspheres was found to be 228 to $608 \mu \mathrm{m}$.

\section{Surface morphology}

Scanning electron microscopy reveals that $F 1$, F3, F4, F5 and F6 formulation produced spherical microspheres as compared to F2 formulation. The microspheres of F2 formulation (prepared with CAP) were of irregular shape with large pores and smooth surface (Fig. 1b). In the last formulation F6 (prepared with EC, CAP \& Eudragit L), the microspheres were of smoothest surface (as compared to others) without any pore formation (Fig. 1d). Scanning electron microscopy confirmed that the microspheres of F1 formulation (Fig. 1a) were the spherical shaped with very rough surface while microspheres of F3, F4 and F5 formulation were hollow nature with small pores on the surface of the microspheres. Formulation F3 (prepared with EC and CAP) showed the presence of drug particles on the surface (Fig. 1C).

Table 2: Physical characteristics of colon-specific microspheres of diclofenac sodium (mean $\pm S D, n=3$ )

\begin{tabular}{lcccccc}
\hline $\begin{array}{l}\text { Formula- } \\
\text { tion }\end{array}$ & $\begin{array}{c}\text { Bulk density } \\
(\mathbf{g} / \mathbf{m l}, \mathbf{\rho b})\end{array}$ & $\begin{array}{c}\text { Tap density } \\
(\mathbf{g} / \mathbf{m l}, \mathbf{\rho t})\end{array}$ & $\begin{array}{c}\text { Compressibility } \\
\text { index }(\%)\end{array}$ & $\begin{array}{c}\text { Particle } \\
\text { size }(\boldsymbol{\mu m})\end{array}$ & $\begin{array}{c}\text { Drug } \\
\text { content }(\%)\end{array}$ & $\begin{array}{c}\text { Angle of } \\
\text { repose }\left({ }^{\circ}\right)\end{array}$ \\
\hline F1 & $0.400 \pm 0.0092$ & $0.434 \pm 0.0595$ & 7.8341 & $323.50 \pm 2.1$ & $90.88 \pm 0.361$ & $34.7 \pm 3.0208$ \\
F2 & $0.313 \pm 0.0142$ & $0.323 \pm 0.0063$ & 3.0959 & $608.30 \pm 3.8$ & $86.43 \pm 0.207$ & $34.8 \pm 1.0614$ \\
F3 & $0.357 \pm 0.0248$ & $0.416 \pm 0.0190$ & 14.1826 & $426.66 \pm 1.9$ & $91.50 \pm 0.316$ & $26.6 \pm 0.9847$ \\
F4 & $0.322 \pm 0.0248$ & $0.344 \pm 0.0323$ & 6.3953 & $533.33 \pm 1.7$ & $78.12 \pm 0.244$ & $32.7 \pm 0.6112$ \\
F5 & $0.318 \pm 0.0142$ & $0.322 \pm 0.0121$ & 2.7950 & $406.25 \pm 3.8$ & $74.49 \pm 0.173$ & $34.6 \pm 2.4005$ \\
F6 & $0.344 \pm 0.0190$ & $0.384 \pm 0.0202$ & 10.4166 & $228.00 \pm 3.2$ & $69.22 \pm 0.237$ & $35.8 \pm 1.2723$ \\
\hline
\end{tabular}
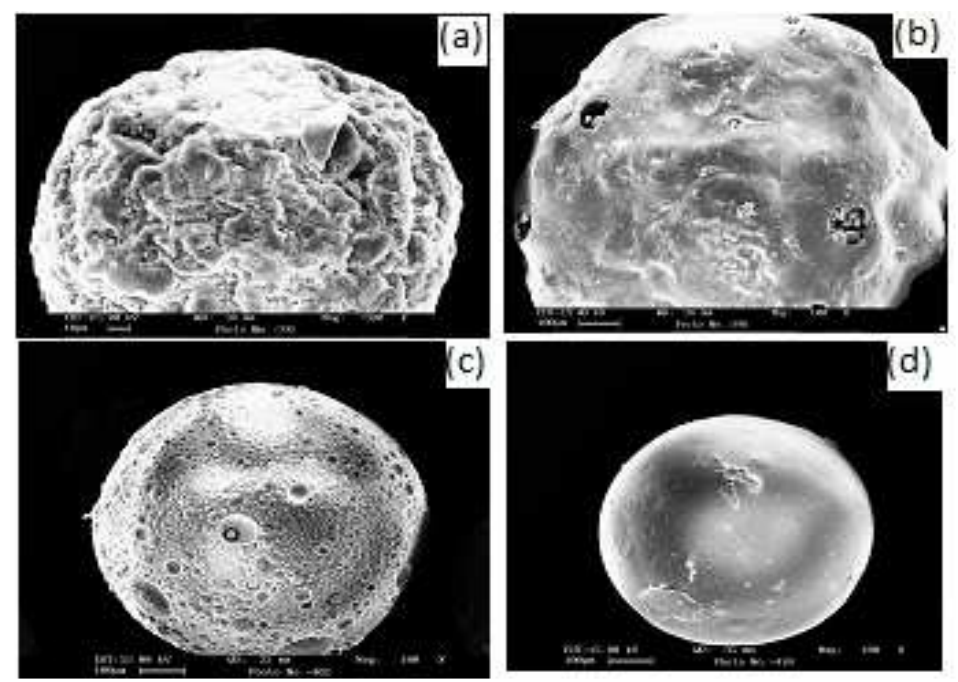

Fig 1: SEM photograph of microsphere formulations (a) F1 (microspheres made of EC); (b) F2 (microspheres made of CAP); F3 (microspheres made of EC and CAP) and; F6 (microspheres made of EC, CAP, and Eudragit L 100-55 combination) 


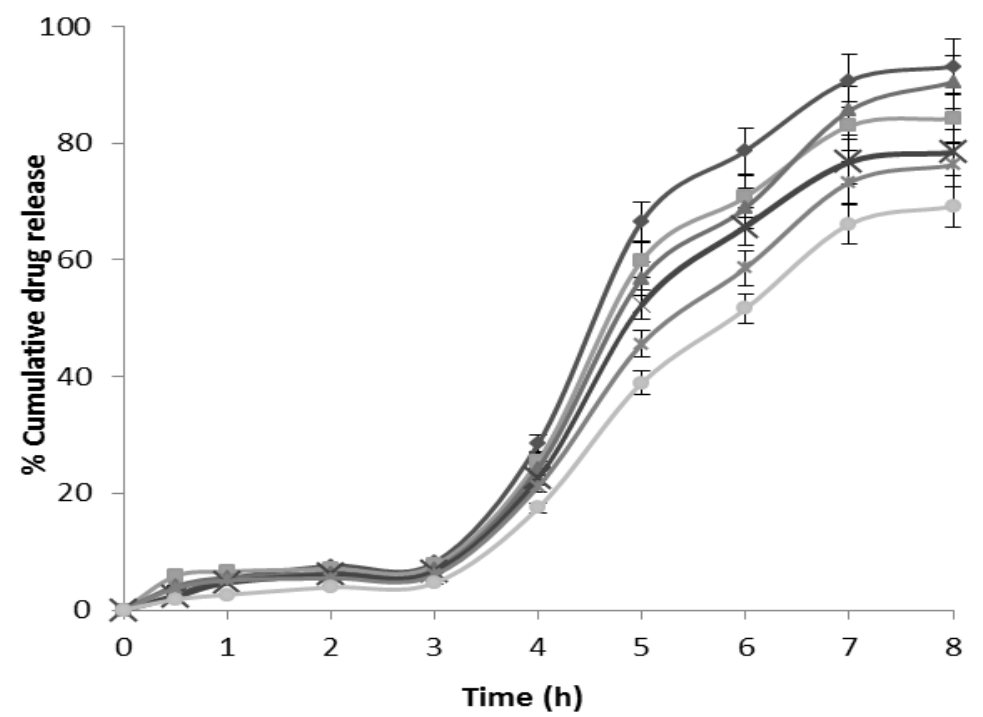

Fig 2: In vitro drug release study of colon specific microspheres of diclofenac sodium F1 ( $)$, F2 (•), F3 ( $(\times)$, F5 $\left({ }^{*}\right)$, F6 $(\bullet)$

\section{In vitro drug release}

In vitro drug release studies of all the formulations were performed in $\mathrm{pH} 6.8$ phosphate buffer at $276 \mathrm{~nm}$ (Fig 2). Drug release from the formulation varied significantly among the different polymers as well as their combination and ratio in the formulations. The drug release at the end of $8 \mathrm{~h}$ was 93.3, 84.82, $90.4,78.9,76.6$, and $69.23 \%$ for formulation $\mathrm{F} 1$, F2, F3, F4, F5 and F6 respectively. Formulation F1 (followed by F3) containing ethyl cellulose showed the maximum release while the formulation $\mathrm{F} 6$ showed the minimum release after the $8 \mathrm{~h}$.

\section{Kinetics of drug release}

The different kinetic models for diclofenac microspheres release were also studied. The release versus time curves were plotted for determining the order of release (zero and first order). It was found that the drug release was of zero order and followed the matrix diffusion process (Higuchi curves i.e. \% drug release versus square root of time, were found linear). However, the formulation F2 did not show the linear Higuchi curves, which indicated that the drug release mechanism from these microspheres was burst effect and not the diffusion controlled.

\section{DISCUSSION}

Delivering diclofenac with the colon targeting not only provides the high concentration in the colon region (where it is required at high dose in colorectal cancer or inflammatory bowl disease) but also helps to avoid the possible gastric irritation (which is common with immediate or conventional release of diclofenac) [19].

All the prepared formulations showed good percent drug loading. The highest percent drug content of Formulation F3 (prepared with EC \& CAP) was well supported by the presence of drug particles on the surface of these microspheres in its SEM. In general, SEM study showed spherical shaped particles with rough and porous surface (except that of formulation F6 which was prepared with EC, CAP \& Eudragit L). The drug release was very less in first $4 \mathrm{~h}$ and when the drug was exposed to the medium mimicking the colon, the drug release was found to be increasing abruptly. This lag time in drug release ensured the delivery of the maximum amount of drug in the colonic $\mathrm{pH}$ and colonic environment. The in vitro drug release study indicated that the combination of polymer and their changed ratio changed the release rate of drug from microspheres. The $\mathrm{F} 1$ formulation containing ethyl cellulose showed maximum release and $\mathrm{F} 2$ formulation containing CAP showed slow release than $\mathrm{F} 1$ at the same ratio of polymer. The ethyl cellulose formed the very rough surface (as confirmed by SEM) of the microspheres through which drug release was maximum by dissolving the layers of rough surface of polymer. The formulation F2 showed biphasic pattern i.e. initial fast release (as above $50 \%$ in only $1 / 2$ h) called as burst effect, due to the large size of pores on the surface of microspheres and then sustained release due to smooth surface. The formulation F3 showed the second highest drug release after $\mathrm{F} 1$. This might be due to decrease in the concentration of EC 
and CAP, which in turn showed the smaller pores on surface (as compared to EC) with little burst effect (due to the CAP).This indicates that the decrease in concentration of the both polymers decreased their characters like roughness, pore formation and burst effect (upon release). This was evident in SEM of F3 which showed smaller pores, roughness and presence of drug particles on the surface. The formulation F4, F5 and F6 showed very slow release rate profile due to Eudragit L 100-55 (practically insoluble in water) polymer as compared to F1, F2 and F3. The slow release effect in these formulations depends on the concentration of the Eudragit $L$ 100-55, which made the polymer solution very viscous at very low concentration [20]. The viscous polymer solution increased the coat thickness, thereby increasing the distance of the diffusional barrier for the drug [21]. Formulations F6 showed better sustained release as compared to others. This slowest release rate profile might be due to increased concentration of Eudragit L 100-55. However, increased concentration of Eudragit showed more uniform, spherical and smaller microcapsules which were evident in SEM (Fig. 1d). Therefore, the release of diclofenac in colon can be targeted through these polymers in case of colorectal cancer where the high localization of drug in and around the cancer cells of colon is required.

\section{CONCLUSION}

Colon specific microspheres of diclofenac sodium using EC, CAP and Eudragit L 100-55 have been successfully prepared. Formulation F3 (prepared with drug: EC: CAP in 1:2:1 ratio) is the optimized preparation and demonstrate potentially suitable drug release for the colonspecific delivery of diclofenac.

\section{ACKNOWLEDGEMENT}

This work was supported by Educational Commission of Project of Mongolia Autonomous Region, China (no. NJ10183), Science and Technology Planning Project of Mongolia Autonomous Region, China (no. 20120403) and Natural Science Foundation of Inner Mongolia Autonomous Region of China (no. 2013MS1106).

\section{REFERENCES}

1. Basit A, Bloor J. Perspectives on colonic drug delivery, Business briefing. Pharmtech 2003; 185-190.

2. Watts P, Illum L. Colonic drug delivery. Drug Dev Ind Pharm 1997; 23: 893-913.
3. Philip AK, Philip B. Colon targeted drug delivery systems: a review on primary and novel approaches. Oman Med J. 2010; 25: 70-78.

4. Smalley W, Ray WA, Daugherty J, Griffin MR. Use of nonsteroidal anti-inflammatory drugs and incidences of colorectal cancer. Arch Intern Med. 1999; 159: 161-166.

5. Collet JP, Sharpe C, Belzile E, Boivin, J.F. Abenhaim, L. Colorectal cancer prevention by non-steroidal antiinflammatory drugs: effects of dosage and timing. $\mathrm{Br}$. J. Cancer 1999; 81: 62-68.

6. Langman $M J$, Cheng KK, Gilman EA, Lancashire RJ. Effect of anti-inflammatory drugs on overall risk of common cancer: case-control study in general practice research database. BMJ 2000; 320: 16421646.

7. Chourasia MK, Jain SK. Pharmaceutical approaches to colon targeted drug delivery systems. J Pharm Pharm Sci. 2003; 6(1): 33-66.

8. Jain A, Sing V, Gupta $Y$, Jain SK, Perspectives of biodegradable natural polysaccharides for sitespecific drug delivery to the colon. I Pharm Pharmaceut Sci. 2007; 10 (1): 86-128.

9. Yoshida T, Lai TC, Kwon GS, Sako K. pH- and ionsensitive polymers for drug delivery. Expert Opin Drug Deliv. 2013; 10(11): 1497-513.

10. Semalty $M$, Yadav S, Semalty A. Preparation and characterization of gastroretentive floating microspheres of ofloxacin hydrochloride. Int. J. Pharm. Sci. Nanotech. 2010; 3: 819-23.

11. Friend DR. Issues in oral administration of locally acting glucocorticosteroids for treatment of inflammatory bowel disease. Aliment Pharmacol Ther, 1998; 12 (7): 591-603.

12. Ilyas M, Straub J, Tomlinson IP, Bodmer WF. Genetic pathways in colorectal and other cancers. Eur $J$ Cancer. 1999; 35 (14): 1986-2002.

13. Patel M, Amin AF. Process optimization and characterization of mebeverine hydrochloride loaded guar gum microspheres for irritable bowel syndrome. Carbohydrate Polymers. 2011; 86 (2): 536-545.

14. Brogen RN, Pakes GE, Speight TM, Avery GS. Diclofenac sodium: $A$ review of its pharmacological properties and therapeutic use in rheumatic diseases and pain of varying origin. Drugs. 1980; 20: 24-48.

15. Mittal N, Kanwar SS, Sanyal SN. Effect of non-steroidal antiinflammatory drugs and the pro-carcinogen 1,2 dimethylhydrazine on the rat intestinal membrane. Nutr Hosp 2008; 23 (5): 439-48.

16. Ciftci, K. Alternative approaches to the treatment of colon cancer. Eur. J. Pharm. Biopharm. 1996; 42: 160-170.

17. Chaurasia M, Chourasia MK, Jain NK, Jain A, Soni V, Gupta $Y$, Jain SK. Cross- linked guar gum microspheres, A viable approach for improved delivery of anticancer drugs for the treatment of colorectal cancer. AAPS PharmSciTech 2006; 7(3): Article 74 . 
18. Shabaraya A, Narayanachrayulu $R$. Design and evaluation of chitosan microspheres of metoprolol tartrate for sustained release. Indian J. Pharm. Sci. 2003; 65: 250-252.

19. Semalty $A$, Semalty $M$, Singh $D$, Rawat MSM, Development and physicochemical evaluation of pharmacosomes of diclofenac, Acta Pharm. 2009; 59: 335-344.
20. Mandal M, Gupta BK. Kinetics of release of pentazocine $\mathrm{HCl}$ from micropellets of ethylcellulose and eudragit RL 100. Indian J. Pharm. Sci. 1997; 59(7): 181-183.

21. Nath B, Nath LK, Mazumdar B. Design and development of Metformin $\mathrm{HCl}$ floating microcapsules using two polymers of different permeability characteristics. Int. J. Pharm. Sci. Nanotech. 2009; 2: 177-186. 